\title{
Desempenho de feijão-caupi influenciado por populações e espaçamentos distintos no sudeste do Pará
}

A expressão do potencial produtivo do feijão-caupi depende da combinação de diversos fatores, incluindo o sistema de produção utilizado, condições de clima e solo da área de cultivo e práticas como o número de plantas por área e espaçamento entre linhas de plantio. Neste contexto, o objetivo foi avaliar a produtividade do feijão-caupi cv BRS Guariba em diferentes populações de plantas e espaçamentos sob condições edafoclimáticas do sudeste paraense, Amazônia brasileira. Para isso, utilizou-se delineamento experimental em blocos casualizados, em fatorial $2 \times 5$, com quatro repetições. Os tratamentos consistiram em dois espaçamentos: 0,4 e 0,5 m; e cinco populações de plantas por hectare: $160.000,220.000,280.000,340.000,400.000$ plantas ha-1. Foram avaliados o número de vagem por planta, número de grãos por vagem, comprimento de vagem $(\mathrm{cm})$, produtividade de grãos $(\mathrm{kg}$ ha-1) e peso de 100 grãos $(\mathrm{g})$. A menor população de plantas (160.000 plantas ha-1) utilizada promoveu o maior número médio de vagem por planta em ambos os espaçamentos. 0 comprimento médio da vagem foi de $21,2 \mathrm{~cm}$, o qual não foi influenciado por nenhum dos fatores estudados. O número de grãos por vagem foi superior em espaçamento de $0,5 \mathrm{~m}(11,8)$ em relação a $0,4 \mathrm{~m}(11,3)$. No entanto, somente houve diferença no número de grãos por vagem entre as populações dentro do menor espaçamento de plantio, com destaque para as maiores populações $(400.000,340.000$ e 280.000 plantas ha-1). A produtividade de grãos variou de 524,7 a $995,1 \mathrm{~kg}$ ha-1, com produtividades superiores correspondendo às populações de $400.000,340.000$ e 280.000 plantas ha-1, independentemente do espaçamento utilizado. Por outro lado, o peso dos grãos foi pouco alterado em função dos tratamentos.

\section{Cowpea performance as influenced by distinct populations and spacing in southest of Pará}

\begin{abstract}
The cowpea productive potential expression depends on the combination of several factors, including the production system used, climate and soil conditions of the cultivation area and practices such as the number of plants per area and spacing between planting lines. In the context, the aim was to evaluate the cowpea cv BRS Guariba productivity in different plants populations and spacing under edaphoclimatic conditions in southeast of Pará, Brazilian amazon. For this, was used a randomized block design, in a $2 \times 5$ factorial, with four replications. The treatments consisted of two spacings: 0.4 and 0.5 m; and five plant populations per hectare: $160.000,220.000,280.000,340.000,400.000$ plants ha-1. Were evaluated the number of pods per plant, number of grains per pod, pod length (cm), grain yield (kg ha-1) and weight of 100 grains (g). The smallest plant population ( 160.000 plants ha-1) used promoted the highest average number of pods per plant in both spacings. The average pod length was $21.2 \mathrm{~cm}$, which was not influenced by any factors studied. The number of grains per pod was higher in spacing of $0.5 \mathrm{~m}$ (11.8) compared to $0.4 \mathrm{~m}$ (11.3). However, there was only a difference in the number of grains per pod between the populations within the smallest planting spacing, with emphasis on the largest populations $(400.000,340.000$ and 280.000 plants ha-1). Grain productivity ranged from 524.7 to $995.1 \mathrm{~kg}$ ha-1, with higher yields corresponding to the populations of $400.000,340.000$ and 280.000 plants ha-1, regardless of the spacing used. On the other hand, the weight of the grains was little changed due to the treatments.
\end{abstract}

Keywords: Vigna unguiculata (L.) Walp; Plants spatial distribution; Agronomic characteristics; Grain productivity.

Topic: Uso Sustentável da Biodiversidade

Reviewed anonymously in the process of blind peer.
Received: 08/02/2020

Approved: 09/03/2020
Fernanda Miruê da Silva (iD)

Universidade Federal Rural da Amazônia, Brasil

http://lattes.cnpq.br/2536402842466763

http://orcid.org/0000-0003-3316-0804

fernanda mirue@hotmail.com

Letícia Cunha da Hungria (DD

Universidade Federal Rural da Amazônia, Brasil

http://lattes.cnpq.br/8199254308606696

http://orcid.org/0000-0002-1038-9799

leth_hungria@hotmail.com

Priscila Pereira Sacramento (D)

Instituto Federal do Pará, Brasil

http://lattes.cnpq.br/5402319622919355

http://orcid.org/0000-0001-6565-9015

priscila.sacrame@gmail.com

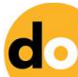

DOI: 10.6008/CBPC2179-6858.2020.002.0013

\author{
Jamil Chaar El-Husny (iD) \\ Embrapa Amazônia Oriental, Brasil \\ http://lattes.cnpq.br/9159556856851214 \\ http://orcid.org/0000-0002-8599-8505 \\ jamil.husny@embrapa.br \\ Luciana da Silva Borges (iD \\ Universidade Federal Rural da Amazônia, Brasil \\ http://lattes.cnpq.br/4533722536181534 \\ http://orcid.org/0000-0002-1194-6411 \\ luciana.borges@ufra.edu.br
}

\section{Referencing this:}

SILVA, F. M.; HUNGRIA, L. C.; SACRAMENTO, P. P.; EL-HUSNY, J. C.; BORGES, L. S.. Desempenho de feijão-caupi influenciado por populações e espaçamentos distintos no sudeste do Pará. Revista Ibero Americana de Ciências Ambientais, v.11, n.2, p.110-117, 2020. DOI: http://doi.org/10.6008/CBPC2179-6858.2020.002.0013 


\section{INTRODUÇÃO}

O feijão-caupi [Vigna unguiculata (L.) Walp] é amplamente cultivado em sistemas agrícolas familiares e tem grande importância social e econômica, sendo considerada uma das principais culturas alimentares, especialmente para populações mais carentes das regiões Norte e Nordeste. A facilidade de produção, acessibilidade e seus altos teores proteicos (20 a 26\%), nutricionais e energéticos são combinações que atraem o interesse pelo cultivo (FROTA et al., 2008).

Na região Norte, embora o feijão-caupi apresente ampla rusticidade, apresenta baixa produtividade de grãos, com média de $861 \mathrm{~kg} \mathrm{ha}^{-1}$. No estado do Pará, a produtividade é ainda menor com média igual a $742 \mathrm{~kg} \mathrm{ha}^{-1}$ (IBGE, 2018). No entanto, os níveis de produtividade e a expressão do potencial produtivo do feijão-caupi dependem da combinação de fatores como o número de plantas por área e o espaçamento entre linhas utilizado no plantio, os quais provocam efeitos diretos sobre as características morfológicas, fisiológicas e de produtividade da cultura, bem como no uso de recursos tecnológicos, ambientais e de manejo (BEZERRA et al., 2012)

O conhecimento da combinação ótima do espaçamento entre fileiras e população de plantas por área é fundamental para maximizar a produção de qualquer cultura. Bezerra et al. (2008), destacam que quando há competição entre plantas em intensidade elevada, principalmente nos estádios iniciais, há grande possibilidade de surgirem plantas improdutivas, resultando em baixo rendimento de grãos. Entretanto, a intensidade da influência desses fatores depende ainda das características da cultivar escolhida, do sistema de manejo adotado e do ambiente de cultivo.

Considerando que os componentes da produtividade de grãos em feijão-caupi são afetados isoladamente e pela interação espaçamento x densidade (CARDOSO et al., 2006; CARDOSO et al., 2008; BEZERRA et al., 2012), a avaliação em ambientes de cultivo distintos faz-se necessária. Isto porque haverá um caráter com maior efeito direto sobre a produtividade de grãos em cada ambiente, em função das diferenças das condições edafoclimáticas entre os locais de condução de cada ensaio (RAMOS et al., 2012). Neste contexto, o objetivo foi avaliar a produtividade do feijão-caupi $c v$ BRS Guariba sob populações de plantas e espaçamentos distintos em condições edafoclimáticas do sudeste paraense, Amazônia brasileira.

\section{MATERIAIS E MÉTODOS}

\section{Descrição da área de estudo}

O experimento foi conduzido no período de abril a julho de 2016, no campo experimental da Embrapa Amazônia Oriental, município de Paragominas (02 59' 45" S e 47ㅇ 21' 10" O), mesorregião do sudeste do estado do Pará, Amazônia brasileira. A área de estudo pertence a uma zona climática tropical chuvosa - Aw (Köppen), com expressivo período de estiagem, temperatura média anual de 26,5 ำ, precipitação média anual de 1.800 mm (RODRIGUES et al., 2003).

O solo da área é do tipo Latossolo Amarelo, textura muito argilosa $\left(15 \mathrm{~g} \mathrm{~kg}^{-1}\right.$ de areia grossa, $19 \mathrm{~g} \mathrm{~kg}^{-}$ ${ }^{1}$ de areia fina, $286 \mathrm{~g} \mathrm{~kg}^{-1}$ de silte e $680 \mathrm{~g} \mathrm{~kg}^{-1}$ de argila), com os seguintes atributos químicos na camada 
superficial (0-20 cm): $\mathrm{pH}\left(\mathrm{H}_{2} \mathrm{O}\right)$ igual a 5,5; $\mathrm{P}$ e K (Mehlich 1) iguais a 2 e $31 \mathrm{mg} \mathrm{dm}^{-3}$, respectivamente; $\mathrm{Ca}$, $\mathrm{Ca}+\mathrm{Mg}, \mathrm{Al}, \mathrm{H}+\mathrm{Al}$ iguais a 3,6; 5,2; 0,1 e 4,8 $\mathrm{cmolc} \mathrm{dm}^{-3}$, respectivamente é saturação por base (V\%) igual a 70 (EMBRAPA, 2011).

\section{Tratamento e delineamento experimental}

O delineamento experimental foi em blocos casualizados, em esquema fatorial $2 \times 5$, com quatro repetições. Os tratamentos consistiram em dois espaçamentos $(0,4$ e $0,5 \mathrm{~m})$ entre linhas de plantio e cinco populações de plantas por hectare $\left(160.000,220.000,280.000,340.000\right.$ e 400.000 plantas ha-1 $^{-1}$. As parcelas experimentais foram compostas por 5 linhas para o espaçamento de 0,4 $\mathrm{m}$ e 4 linhas para o espaçamento de 0,5 m, e cada linha com 5 metros de comprimento, totalizando 40 parcelas. Duas fileiras centrais de plantas foram consideradas a área útil para o espaçamento de $0,5 \mathrm{~m}$ e as três fileiras centrais para o espaçamento de $0,4 \mathrm{~m}$, desprezando $0,5 \mathrm{~m}$ de bordadura em cada extremidade.

\section{Plantio e manutenção em campo}

A semeadura do feijão-caupi foi realizada manualmente, depositadas três sementes por cova. Todas as parcelas receberam calagem com aplicação de calcário dolomítico $\left(2,2 \mathrm{t}\right.$ ha $\left.{ }^{-1}\right)$ e adubação em função dos resultados da análise química do solo. Aplicou-se o equivalente a $300 \mathrm{~kg} \mathrm{ha}^{-1}$ da fórmula fertilizante 10-2820 (NPK), correspondendo a $10 \mathrm{~kg}$ de N, $28 \mathrm{~kg}$ de $\mathrm{P}_{2} \mathrm{O}_{5}$ e $20 \mathrm{~kg}$ de $\mathrm{K}_{2} \mathrm{O}$, com adubação realizada em fundação. Com o sintoma de deficiência foi realizado uma adubação de cobertura 30 dias após a emergência com $40 \mathrm{~kg}$ ha-1 de N.

Foi aplicado 2,4-D com dosagem de 1,5 $\mathrm{L} \mathrm{ha}^{-1}$ e glifosato com dosagem de $3 \mathrm{~L} \mathrm{ha-1}$ para dessecação da área, 45 dias antes da implantação do experimento. Foram realizadas duas aplicações de inseticida Engeo Pleno (Tiametoxam) na dosagem de $125 \mathrm{~mL} /$ ha para o controle de Vaquinha (Diabrotica speciosa) e Mosca Branca (Bemisia tabaci) e uma aplicação de inseticida Tiger (Piriproxifem) na dosagem $250 \mathrm{~mL} \mathrm{ha-1} \mathrm{em} 250 \mathrm{~L}$ de calda para controle de Mosca Branca.

\section{Características da cultivar}

A cultivar BRS Guariba foi obtida através do cruzamento das linhagens IT85F-2687, International Institute of Tropical Agriculture - IITA, da Nigeria, com a TE87-98-8G, do programa de melhoramento da Embrapa Meio-Norte em Teresina/Pi. O ciclo total da cultivar é considerado curto (70 dias), com floração aos 41 dias, porte semiereto, colocação dos grãos branco, planta de porte médio e teor de proteína de 22\%.

A cultivar apresenta resistência ao mosaico, doença transmitida pelo pulgão (Cowpea aphid-borne mosaic virus - CABMV), ao mosaico-dourado (Cowpea golden mosaic virus - CGMV), é moderadamente resistente ao Oídio (Erysiphe polygoni DC.), e a mancha-café (Colletotrichum truncatum (Schw. Andrus \& Moore)), e é tolerante a altas temperaturas (GONÇALVES et al., 2009). 


\section{Coleta de dados}

Aos 76 DAS (dias após a semeadura), na ocasião da colheita, foram avaliados o número médio de vagens por planta (NVP) em dez plantas, o número de grãos por vagem (NGV) e o comprimento da vagem (CMV) (cm) em dez vagens coletadas ao acaso em todos os tratamentos, o peso de 100 grãos (P100) (g) e a produtividade de grãos (PROD) $\left(\mathrm{kg} \mathrm{ha}^{-1}\right)$. A produtividade foi quantificada pela produção total de grãos nas áreas úteis das parcelas e o peso de cem grãos correspondeu ao peso médio de três amostras com correção da umidade para $13 \%$.

\section{Análise de dados}

Os dados coletados foram submetidos à análise de variância (ANOVA) para avaliar os efeitos da utilização de espaçamentos e populações de plantas distintas sobre as componentes de produção. Quando significativas, as médias foram comparadas pelo teste de Tukey $(p<0,05)$ por meio do software SISVAR, versão 5.6 (FERREIRA, 2011).

\section{RESULTADOS E DISCUSSÃO}

Os resultados da análise de variância dos componentes de produtividade são apresentados na Tabela 2. Apenas o NGV foi influenciado pelo espaçamento, isoladamente, enquanto a população de plantas provocou efeito sobre NVP, NGV e PROD. Quando avaliada a interação espaçamento versus população observou-se a influência sobre o NGV, P100 e PROD. Não foi observada influência de nenhum dos fatores sobre o CMV.

Tabela 1: Resumo das análises de variância para número de vagem por planta (NVP), comprimento de vagem (CV-cm), número de grãos por vagem (NGV), peso de 100 grãos (P100) e produtividade de grãos (PROD).

\begin{tabular}{|l|l|l|l|l|l|l|}
\hline \multirow{2}{*}{ FV } & \multicolumn{9}{l|}{ Quadrado Médio } \\
\cline { 2 - 7 } & GL & NVP & CMV(cm) & NGV & P100 (g) & PROD $\left(\mathrm{kg}^{\text {ns }}{ }^{-1}\right)$ \\
\hline Espaçamento (E) & 1 & $0,42^{\text {ns }}$ & $1,15^{\text {ns }}$ & $280,90^{*}$ & $2,86^{\text {ns }}$ & $23123,59^{\text {ns }}$ \\
\hline População (P) & 4 & $3,57^{*}$ & $0,96^{\text {ns }}$ & $422,60^{*}$ & $1,53^{\text {ns }}$ & $219704,77^{*}$ \\
\hline Ex P & 4 & $0,29^{\text {ns }}$ & $0,36^{\text {ns }}$ & $192,40^{*}$ & $6,64^{*}$ & $49960,31^{*}$ \\
\hline Erro & 30 & 0,10 & 0,66 & 38,45 & 1,39 & 13460,78 \\
\hline CV (\%) & - & 10,83 & 3,85 & 5,34 & 5,44 & 14,38 \\
\hline
\end{tabular}

${ }^{n s}$ Não significativo; * Significativo a $5 \%$ de probabilidade, pelo teste $\mathrm{F}$.

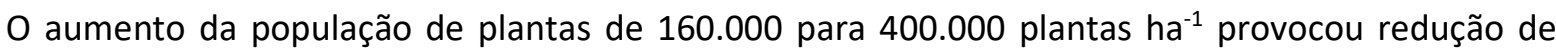
$36,11 \%$ no NVP, que diminuiu de 3,6 para 2,3 , dentro do espaçamento de $0,4 \mathrm{~m}$. Por outro lado, quando as fileiras foram espaçadas de 0,5 m ocorreu redução de 35,12\% do NVP quando a população foi aumentada de 160.000 para 220.000 plantas ha-1 ${ }^{-1}$ com médias de 4,47 e 2,90, respectivamente, e não havendo, a partir desta última, diferença entre as demais populações (Tabela 2).

O NVP é um dos principais componentes de produção do feijão-caupi e estes resultados sugerem que a BRS Guariba, nas condições edafoclimáticas do estudo, apresentam médias mínimas de 2,30 e 2,42; e máximas de 3,60 e 4,47 de NVP para os espaçamentos de 0,4 e 0,5 m, nesta ordem. Além disso, a cultivar atingiu o seu limite mínimo de NVP induzida pela competição intraespecífica de alta intensidade. 
Tabela 2: Valores médios de número de vagem por planta (NVP), número de grãos por vagem (NGV) e comprimento de vagem (CMV) em feijão-caupi $c v$ BRS Guariba sob cinco populações de plantas e dois espaçamentos entre linhas.

\begin{tabular}{|l|l|l|l|l|l|l|l|l|l|}
\hline \multirow{2}{*}{ Plantas ha $^{-1}$} & NVP & NGV & \multicolumn{1}{l|}{ CMV } \\
\cline { 2 - 10 } & $0,4 \mathrm{~m}$ & $0,5 \mathrm{~m}$ & Média & $0,4 \mathrm{~m}$ & $0,5 \mathrm{~m}$ & Média & $0,4 \mathrm{~m}$ & $0,5 \mathrm{~m}$ & Média \\
\hline 160.000 & $3,60 \mathrm{Ab}$ & $4,47 \mathrm{Aa}$ & $4,04 \mathrm{~A}$ & $10,0 \mathrm{Bb}$ & $11,6 \mathrm{Aa}$ & $10,8 \mathrm{~B}$ & $21,2 \mathrm{~A}$ & $21,0 \mathrm{~A}$ & $21,0 \mathrm{~A}$ \\
\hline 220.000 & $2,92 \mathrm{BCa}$ & $2,90 \mathrm{Ba}$ & $2,91 \mathrm{~B}$ & $10,5 \mathrm{Bb}$ & $11,6 \mathrm{Aa}$ & $10,8 \mathrm{~B}$ & $21,5 \mathrm{~A}$ & $22,0 \mathrm{~A}$ & $21,7 \mathrm{~A}$ \\
\hline 280.000 & $2,97 \mathrm{Aba}$ & $2,95 \mathrm{Ba}$ & $2,96 \mathrm{~B}$ & $12,2 \mathrm{Aa}$ & $12,0 \mathrm{Aa}$ & $12,1 \mathrm{~A}$ & $21,0 \mathrm{~A}$ & $21,1 \mathrm{~A}$ & $21,0 \mathrm{~A}$ \\
\hline 340.000 & $2,30 \mathrm{Ca}$ & $2,47 \mathrm{Ba}$ & $2,38 \mathrm{C}$ & $12,3 \mathrm{Aa}$ & $12,0 \mathrm{Aa}$ & $12,1 \mathrm{~A}$ & $20,4 \mathrm{~A}$ & $21,2 \mathrm{~A}$ & $21,0 \mathrm{~A}$ \\
\hline 400.000 & $2,40 \mathrm{BCa}$ & $2,42 \mathrm{Ba}$ & $2,41 \mathrm{C}$ & $12,2 \mathrm{Aa}$ & $12,2 \mathrm{Aa}$ & $12,2 \mathrm{~A}$ & $21,1 \mathrm{~A}$ & $22,0 \mathrm{~A}$ & $21,4 \mathrm{~A}$ \\
\hline Média & $2,84 \mathrm{a}$ & $3,04 \mathrm{a}$ & 2,94 & $11,3 \mathrm{~b}$ & $11,8 \mathrm{a}$ & 11,6 & $21,0 \mathrm{a}$ & $21,4 \mathrm{a}$ & 21,2 \\
\hline
\end{tabular}

Médias seguidas de letras maiúsculas distintas na coluna e letras minúsculas diferentes nas linhas diferem pelo teste de Tukey $(p<0,05)$.

Bezerra et al. (2012), ao avaliarem o comportamento morfoagronômico da mesma cultivar submetida a diferentes densidades populacionais no estado do Piauí, encontraram média mínima de 4,2 e máxima de 11,6 do NVP para as densidades de 500 e 100 mil plantas ha-1, respectivamente. As médias encontradas por esses autores foram superiores as médias registradas neste estudo. Ressalta-se, porém, que Rocha et al. (2007) ao avaliarem a estabilidade das componentes de produção da cultivar BRS Guariba enfatizaram que a cultivar é instável e apresenta interação positiva com o ambiente.

Reduções no NVP em resposta ao aumento da população de plantas ha-1 foram obtidas também por Naim et al. (2010) e Bezerra et al. (2009), com estes últimos autores observando, no estado do Piauí, redução

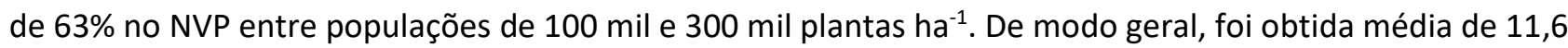
para NGV, com média superior para o espaçamento de $0,5 \mathrm{~m}(11,8)$ em relação ao de $0,4 \mathrm{~m}(11,3)$ (Tabela 2). Quando avaliadas as populações de plantas, foi verificada média de 12,1 para o NGV entre as populações de 280, 340 e 400 mil plantas ha-1 ${ }^{-1}$ incremento de $11 \%$ em relação às menores densidades, que não diferiram entre si. Este efeito foi observado dentro do menor espaçamento $(0,4 \mathrm{~m})$, enquanto no de $0,5 \mathrm{~m}$ não houve diferença entre as diferentes populações.

O NGV é uma componente de produção fundamental para a seleção de cultivares, por exemplo, em virtude de sua relação direta com a produtividade de grãos. Dutra et al. (2015), avaliando o desempenho de feijão-caupi cv. BRS Guariba encontrou NGV médio de 10, 1 e associou o baixo número ao tamanho razoável dos grãos que ocupam mais espaços no interior de uma vagem. Tegliaferre et al. (2013) encontraram números semelhantes, registrando média de 12 grãos por vagem. Esses autores confirmam a performance dos valores obtidos para esta variável neste estudo.

Para o CMV, a média geral obtida foi de $21,2 \mathrm{~cm}$, não apresentando influência do espaçamento e mesmo com o incremento da competição inter e intraplanta provocada pela alta densidade de plantas (Tabela 2). O CMV médio encontrado neste estudo está dentro da faixa considerada padrão comercial (acima de $20 \mathrm{~cm}$ ). Em seus ensaios, Cardoso et al. (2008) e Santos (2013) também não observaram diferença no comprimento de vagens em função de densidades de plantio distintas utilizadas. Trabalhando com a mesma cultivar, Ramos et al. (2014) alcançaram comprimento médio de vagem de até $17,57 \mathrm{~cm}$.

A produtividade de grãos variou de 524,7 a $995,1 \mathrm{~kg} \mathrm{ha}^{-1}$ e foi influenciada pela população de plantas, isoladamente, e pela interação população versus espaçamento (Figura 2). As maiores produtividades, independentemente do espaçamento, foram obtidas quando utilizadas $400.000,340.000$ e 280.000 plantas 
$\mathrm{ha}^{-1}$, que corresponderam às médias de 971,$1 ; 941,0$ e $854,7 \mathrm{~kg} \mathrm{ha}^{-1}$, respectivamente. Este resultado foi observado dentro do espaçamento de 0,4 m e próximo ao registrado para o espaçamento de $0,5 \mathrm{~m}$.

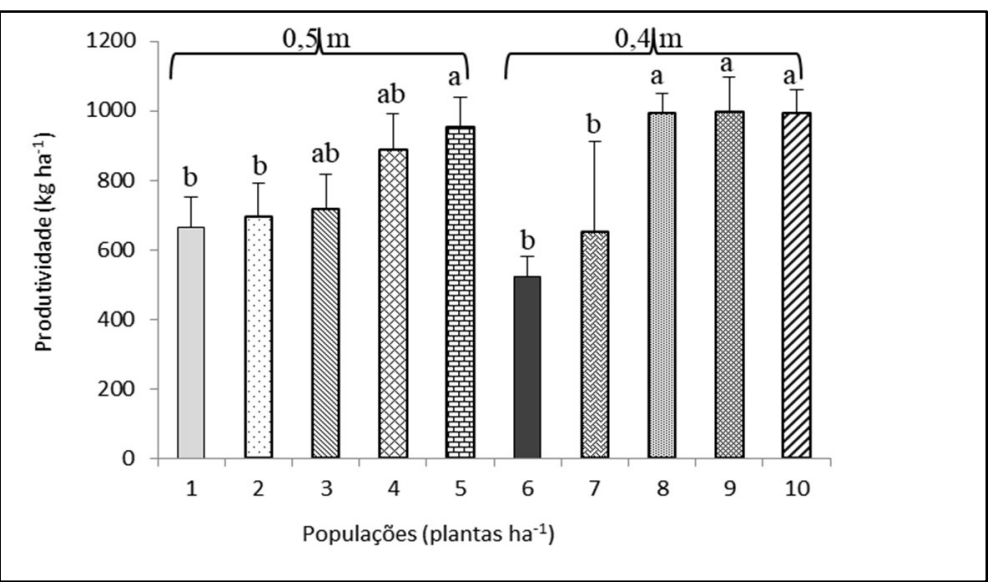

Figura 1: Produtividade de grãos (kg.ha $\left.{ }^{-1}\right)$ de feijão-caupi $c v$ BRS Guariba com cinco populações de plantas $(1=160.000 ; 2=220.000 ; 3=280.000 ; 4=340.000 ; 5=400.000 ; 6=160.000 ; 7=220.000 ; 8=280.000 ; 9=340.000 ; 10=400.000$ plantas.ha- ${ }^{-1}$ ) em espaçamentos entre linhas de $0,5 \mathrm{~m} \mathrm{e} \mathrm{0,4} \mathrm{m}$. Médias seguidas de letras distintas diferem pelo teste de Tukey $(p<0,05)$.

As alterações na população de plantas proporcionam diferenças significativas nas componentes de produção, incluindo o rendimento de grãos (BEZERRA et al., 2012). Teixeira et al. (2010), avaliando o comportamento agronômico de feijão-caupi $c v$ BRS Guariba nas condições edafoclimáticas do sudeste goiano, registrou média de $2221 \mathrm{~kg} \mathrm{ha}^{-1}$ para rendimento de grãos, utilizando espaçamento de $0,7 \mathrm{~m}$ e 10 plantas $\mathrm{m}^{-1}$. Em experimento conduzido por Locatelli et al. (2014), foi encontrada média de $1.170 \mathrm{~kg} \mathrm{ha}^{-1}$ para a cultivar BRS Guariba, no cerrado de Roraima. Em outro estudo, no sudoeste tocantinense, foi registrado para a mesma cultivar produtividade de até $1.222 \mathrm{~kg} \mathrm{ha}^{-1}$ quando utilizado espaçamento de $0,7 \mathrm{~m}$ (SANTOS et al., 2018).

A combinação adequada de densidade de plantas e espaçamento em feijão-caupi pode induzir o aumento da fixação de $\mathrm{N}_{2}$ por área resultando em aumento de produtividade (MAKOI et al., 2009; BELANE et al., 2010). O P100 apresentou média de 21,40 g quando utilizado o espaçamento de 0,5 m e nenhuma alteração significativa foi observada com o incremento de plantas por metro linear (Tabela 3). No espaçamento de 0,4 $\mathrm{m}$ houve pouca alteração do P100, com maior média (23,35 g) promovida pela

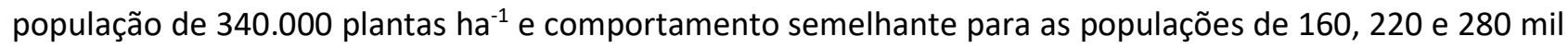
plantas por hectare.

Tabela 3: Peso médio de 100 grãos (g) em feijão-caupi cv BRS Guariba sob cinco populações (plantas ha-1) de plantas e dois espaçamentos entre linhas.

\begin{tabular}{|l|l|l|l|}
\hline \multirow{2}{*}{ Plantas ha } & \multicolumn{2}{|l|}{} & \multirow{2}{*}{ M100 $(\mathrm{g})$} \\
\cline { 2 - 3 } & $0,4 \mathrm{~m}$ & $0,5 \mathrm{~m}$ & Média \\
\hline 160.000 & $22,03 \mathrm{Aba}$ & $22,30 \mathrm{Aa}$ & $22,16 \mathrm{~A}$ \\
\hline 220.000 & $20,95 \mathrm{Aba}$ & $22,48 \mathrm{Aa}$ & $21,71 \mathrm{~A}$ \\
\hline 280.000 & $22,45 \mathrm{Aba}$ & $20,25 \mathrm{Ab}$ & $21,35 \mathrm{~A}$ \\
\hline 340.000 & $23,35 \mathrm{Aa}$ & $20,65 \mathrm{Ab}$ & $22,00 \mathrm{~A}$ \\
\hline 400.000 & $20,90 \mathrm{Ba}$ & $21,33 \mathrm{Aa}$ & $21,11 \mathrm{~A}$ \\
\hline Média & $21,94 \mathrm{a}$ & $21,40 \mathrm{a}$ & 21,67 \\
\hline
\end{tabular}

Médias seguidas de letras maiúsculas distintas na coluna e letras minúsculas diferentes nas linhas diferem pelo teste de Tukey $(p<0,05)$. 
Ressalta-se que o tamanho dos grãos tem relação direta com estes resultados, influenciando o peso de cada grão. Além disso, o peso do grão é intrínseco especialmente a genética do material testado. Os resultados deste estudo corroboram com as médias encontradas por Teixeira et al. (2010) e Dutra et al. (2015) na ordem de 19 g para o peso de 100 grãos para a cultivar BRS Guariba.

\section{CONCLUSÕES}

O aumento das densidades de plantas reduziu o número de vagens por planta em ambos os espaçamentos e induziu ao aumento do número de grãos por vagem dentro do espaçamento de 0,4 m. As maiores produtividades de grãos de feijão-caupi (716 a $995 \mathrm{~kg} \mathrm{ha}^{-1}$ ) foram alcançadas com as maiores populações $\left(280.000,340.000\right.$ e 400.000 plantas ha ${ }^{-1}$ ), independentemente do espaçamento utilizado. A densidade de plantas e espaçamento entre linhas provocaram pouco efeito sobre o peso de 100 grãos e nenhuma influência no comprimento de vagens.

\section{REFERÊNCIAS}

BELANE, A. K.; DAKORA, F. D.. Symbiotic $N_{2}$ fixation in 30 fieldgrown cowpea (Vigna unguiculata L. Walp.) genotypes in the Upper West Region of Ghana measured using $15 \mathrm{~N}$ natural abundance. Biology and Fertility of Soils, v.46, n.2, p.191-198, 2010. DOI: http://doi.org/10.1007/s00374-009$\underline{0415-6}$

BEZERRA, A. A. C.; ALCÂNTARA NETO, F.; NEVES, A. C.; MAGGIONI, K.. Comportamento morfoagronômico de feijãocaupi, cv. BRS Guariba, sob diferentes densidades de plantas. Revista Ciências Agrárias, Belém, v.55, n.3, p.184189, 2012. DOI: http://doi.org/10.4322/rca.2012.059

BEZERRA, A. A. C.; TÁVORA, F. J. A. F.; FREIRE FILHO, F. R.. Morfologia e produção de grãos em linhagens modernas de feijão-caupi submetidas a diferentes densidades populacionais. Revista de Biologia e Ciências da Terra, Campina Grande, v.8, n.1, p.1-9, 2008.

BEZERRA, A. A. C.; TÁVORA, F. J. A. F.; FREIRE FILHO, F. R.; RIBEIRO, V. Q.. Características de dossel e de rendimento em fei j ao-Vigna ereto em diferentes densidades populacionais. Pesquisa Agropecuária Brasileira, Brasília, v.44, n.10, p.1239-1245, 2009. DOI: http://doi.org/10.1590/S0100$\underline{204 \times 2009001000005}$

EMBRAPA. Empresa Brasileira de Pesquisa Agropecuária. Manual de análises químicas de solos, plantas e fertilizantes. Brasília: Embrapa, 2011.

CARDOSO, M. J.; RIBEIRO, V. Q.. Desempenho agronômico do feijão-caupi, cv. Rouxinol, em função de espaçamento entre linhas e densidade de plantas sob regime de sequeiro. Revista Ciência Agronômica, Fortaleza, v.37, n.1, p.102-105, 2006.

CARDOSO, M. J.; RIBEIRO, V. Q.; BASTOS, E. A.; SETUBAL, J. W.. Desempenho agronômico do feijão-caupi, cv. Nova Era, em função do espaçamento entre linhas e densidade de plantas. Horticultura Brasileira, v.26, p.1711-S1714, 2008.

DUTRA, A. F.; MELO, A. S.; FILGUEIRAS, L. M. B.; SILVA, A. R.
F.; OLIVEIRA, I. M.; BRITO, M. E. B.. Parâmetros fisiológicos e componentes de produção de feijão-caupi cultivado sob deficiência hídrica. Revista Brasileira de Ciências Agrárias, v.10, n.2, p.189-197, 2015. DOI:

http://dx.doi.org/10.5039/agraria.v10i2a3912

FERREIRA, D. F.. Sisvar: a computer statistical analysis system. Ciência e Agrotecnologia, v.35, n.6, p.1039-1042, 2011.

FROTA, K. M. G.; SOARES, R. A. M.; ARÊAS, J. A. G.. Composição química do feijão-caupi (Vigna unguiculata $\mathrm{L}$. Walp), cultivar BRS Milênio. Ciência e Tecnologia de Alimentos, v. 28, n. 2, p. 407-476, 2008.

GONÇALVES, J. R. P.; FONTES, J. R. A.; DIAS, M. C.; ROCHA, M. M.; FREIRE FILHO, F. R.. BRS Guariba: cultivar de feijão caupi para o estado do Amazonas. Manaus: Embrapa Amazônia Ocidental, 2009.

IBGE. Instituto Brasileiro de Geografia e Estatística. Produção Agrícola Municipal (PAM). Rio de Janeiro: IBGE, 2018.

LOCATELLI, V. E. R.; MEDEIROS, R. D.; SMIDERLE, O. J.; ALBUQUERQUE, J. A. A.; ARAÚJO, W. F.; SOUZA, K. T. S.. Componentes de produção, produtividade e eficiência da irrigação do feijão-caupi no cerrado de Roraima. Revista Brasileira de Engenharia Agrícola e Ambiental, v.18, n.6, p.574-580, 2014. DOI: http://dx.doi.org/10.1590/S1415$\underline{43662014000600002}$

MAKOI, J. H. J. R.; CHIMPHANGO, S. B. M.; DAKORA, F. D.. Effect of legume plant density and mixed culture on symbiotic $\mathrm{N}_{2}$ fixation in five cowpea [Vigna unguiculata (L.) Walp] genotypes in South Africa. Symbiosis, v.48, p.57-67, 2009. DOI: http://dx.doi.org/10.1007/BF03179985

NAIM, A. M.; JABERELDAR, A. A.. Effect of Plant density and Cultivar on Growth and Yield of Cowpea (Vigna unguiculata L.Walp). Australian Journal of Basic and Applied Sciences, v.4, n.8, p.3148-3153, 2010. 
RAMOS, H. M. M.; BASTOS, E. A.; CARDOSO, M. J.; RIBEIRO, V. Q.; NASCIMENTO, F. N.. Produtividade de grãos verdes do feijão-caupi sob diferentes regimes hídricos. Engenharia Agrícola, Jaboticabal, v.34, n.4, p.683-694, 2014.

RAMOS, H. M. M.; BASTOS, E. A.; ANDRADE JÚNIOR, A. S.; MAROUELLI, W. A.. Estratégias ótimas de irrigação do feijãocaupi para produção de grãos verdes. Pesquisa Agropecuária Brasileira, v.47, p.576-583, 2012.

ROCHA, M. M.; FREIRE FILHO, F. R.; RIBEIRO, V. Q.; CARVALHO, H. W. L.; BELARMINO FILHO, J.; RAPOSO, J. A. A.; ALCÂNTARA, J. P.; RAMOS, S. R. R.; MACHADO, C. F.. Adaptabilidade e estabilidade produtiva de genótipos de feijão-caupi de porte semiereto na região Nordeste do Brasil. Pesquisa Agropecuária Brasileira, v.42, n.9, p.12831289, 2007. DOI: http://dx.doi.org/10.1590/S0100204X2007000900010

RODRIGUES, T. E.; SILVA, R. C.; SILVA, J. M. L.; OLIVEIRA, R. C.; GAMA, J. R. N. F.; VALENTE, M. A.. Caracterização e classificação dos solos do município de Paragominas, estado do Pará. Belém: Embrapa Amazônia Oriental, 2003.
SANTOS, M. G.; ROCHA, W. S.; PRATES, G. R.; RIBEIRO, M. A.; BARROS, A. P. R.; SAKAY, T. R. P.; SANTOS, M. M.. População de plantas em feijão caupi cultivado na várzea e cerrado. Tecnologia \& Ciência Agropecuária, João Pessoa, v.12, n.4, p.21-26, 2018.

SANTOS, J. F.. Resposta do feijão-caupi a diferentes densidades de plantas em Neossolo Regolítico no Agreste Paraibano. Tecnologia \& Ciência Agropecuária, João Pessoa, v.7, n.4, p.37-41, 2013.

TEGLIAFERRE, C.; SANTOS, T. J.; SANTOS, L. C.; SANTOS NETO, I. J.; ROCHA, F. A.; PAULA, A.. Características agronômicas do feijão caupi inoculado em função de lâminas de irrigação e de níveis de nitrogênio. Revista Ceres, v.60, n.2, p.242-248, 2013. DOI: http://dx.doi.org/10.1590/S0034$\underline{737 \times 2013000200013}$

TEIXEIRA, I. R.; SILVA, G. C.; OLIVEIRA, J. P. R.; SILVA, A. G.; PELÁ, A.. Desempenho agronômico e qualidade de sementes de cultivares de feijão-caupi na região do cerrado. Revista Ciência Agronômica, Fortaleza, v.41, n.2, 2010.

A CBPC - Companhia Brasileira de Produção Científica (CNPJ: 11.221.422/0001-03) detém os direitos materiais desta publicação. Os direitos referem-se à publicação do trabalho em qualquer parte do mundo, incluindo os direitos às renovações, expansões e disseminações da contribuição, bem como outros direitos subsidiários. Todos os trabalhos publicados eletronicamente poderão posteriormente ser publicados em coletâneas impressas sob coordenação da Sustenere Publishing, da Companhia Brasileira de Produção Científica e seus parceiros autorizados. Os (as) autores (as) preservam os direitos autorais, mas não têm permissão para a publicação da contribuição em outro meio, impresso ou digital, em português ou em tradução. 